\title{
Erratum to: Growth of different morphologies of silver submicrostructures: The effect of concentrations and $\mathrm{pH}$
}

Fang Liao $\cdot$ Zhou-Feng Wang $\cdot$ Xing-Qi Hu

Published online: 13 May 2011

(C) Springer-Verlag 2011

Erratum to: Ionics (2011) 17:81-86

DOI 10.1007/s11581-010-0497-z

Ionics (2011) 17:177-182

DOI 10.1007/s11581-010-0499-x

These articles were published twice in Ionics, Volume 17 Issue 1, February 2011, p 81-86 (10.1007/s11581-0100497-z) and Ionics, Volume 17 Issue 2, March 2011, p 177-182 (10.1007/s11581-010-0499-x). Please refer to the first publication.

The Authors and Editors apologize for this mistake.

The online version of the original article can be found at http://dx.doi.org/ 10.1007/s11581-010-0497-z and http://dx.doi.org/10.1007/s11581-0100499-x.

F. Liao $(\bowtie) \cdot$ Z.-F. Wang

Chemical Synthesis and Pollution Control Key Laboratory of

Sichuan Province, China West Normal University,

Nanchong 637002, China

e-mail: liaozhang2003@163.com

F. Liao $\cdot$ X.-Q. Hu

Institute of Chemistry and Chemical Engineering,

Southwest Petroleum University,

Xindu 610500, China 